\title{
The Plausible Research Strategies and Tools for Organic Chemists in the Hibernating Stage of Their Pre-PhD
}

\author{
Narayan P. Firke \\ Fergusson College, Autonomous
}

It has been observed that there is an increase in the number of candidates applying for the PhD course (organic chemistry in the present context) as compared to the number of seats available in general all over the globe. This creates a queue and waiting for the scholars to access the chemical laboratory and the mentor at the same time, leading to a break in their career for a couple of months (years in some cases). The present article sheds some light on the possible research strategies for organic chemists in their early developing stage of the pre-PhD based on availability and unavailability of the laboratory.

Keywords: chemistry education, organic chemistry, UGC-CSIR, junior research fellowship, higher education, problem solving, decision making

\section{INTRODUCTION}

When you start on your journey to Ithaca,

Then pray that the road is long,

Full of adventure, full of knowledge .... C. P. Cavafy (Nicolaou, et. al., 1998, p.1233).

Having said so, there are indeed roads full of delays and waiting in the chemical research. As in writing the article chemist/authors emphasize the reactions of those who worked and try to hide or diminish the failed ones. Similarly, the number of years taken by the candidate to get admitted for the PhD course remains under the carpet. This not only changes the start line in one's career but also causes severe monetary and opportunities losses. Students may find themselves struggling to get a suitable position in their own country or abroad. Sometimes natural calamities like current unprecedented COVID-19 pandemic situations all over the globe, in addition, change in the political scenario results in continuous change in education policies of the countries. After the dawn of globalization (Laursen, et. al., 2014), applications for $\mathrm{PhD}$, the student exchange program has accelerated to its maximum extent all over the globe. When this was the case, recommendation, English proficiency and aptitude test were considered as the qualifying and selection criteria for the candidate to be selected in a developed country. In changing times, reasonably good publications are added as one of the criteria in most of the high ranked universities for admission to the $\mathrm{PhD}$ program.

Based on the availability of laboratory the strategies and tools can be divided into two parts. 


\section{Laboratory Dependent Strategies and Tools}

- Often, total synthesis is a dream for every organic chemist (Nicolaou, et. al., 1998), however, it will be early to jump into it as one's goal is to get a PhD position. Nevertheless, Small molecule, derivative, analogues synthesis are tentative possibilities. Synthesis of recently isolated and published small molecules can be attempted by doing retrosynthesis analysis and practically attempted in the laboratory. (El-Elimat, Figueroa, Raja, Graf, Adcock, Kroll, Day, Wani, Pearce \& Oberlies, 2013).

- Here is an example, Betulinan $\mathrm{C}$ is a quinone molecule reported in 2013 which bears simple substitution was synthesis by following scheme (Firke, et. al., 2014). Preparation of derivatives and their biological activities or material applications of recently reported molecules can be one of the best ways to enter into the organic syntheses career. (Firke, Markandeya, Deshmukh, \& Pingale, 2018).

- Isolation/phytochemistry: Targeted natural products search: If you are inspired towards a particular natural product or molecule then you can gather enormous information from the internet and make the archive, which will help you to write a review or work on it. Searching the information about the organic compounds becomes easy when you have the IUPAC, trivial, trade name or scientific names of the plant from which it has been isolated e.g. Taxol or paclitaxel. The field of natural product research has enormous potential to the beginner where the things required for this research are limited and readily available in the literature surveys.

- Solvent purification and drying: A good organic chemist has many skills associated with them, one of them is solvent purification and drying which is a prerequisite for many organic reactions (Williams \& Lawton, 2010; Armarego \& Perrin, 2000).

- Marine natural products: if you have access to the ocean then you may dive in isolation or semisynthesis of the marine natural product.

- Collaboration not only adds to your research experience but teaches you interpersonal skills which are required in day-to-day activities. Even fishermen can be your collaborator if you are working on some marine natural products isolation or semi-synthesis.

- Internship at an industry or research institute provides a wholesome experience of working in organic laboratories, if a candidate has such access should always go for it.

- Biological activities: Indeed, every organic molecule has some or other biological activity, the only thing we have to discover and reveal to the scientific community. Doing so working or collaborating with microbiology laboratories may help organic chemists find opportunities in their career e.g. antibacterial antifungal activity of the organic compounds can be easily tested using the zone inhibition method in microbiology laboratories under expert supervision.

- Truly speaking, approximately half of the organic chemistry laboratory tasks are analytical techniques, so a good organic chemist has to master column chromatography, TLC, HPLC, GC, NMR, LC-MS/MS, Chemdraw structure drawing (Tantillo, 2018) proficiency etc. while structure determination of an organic molecule.

- Ethnopharmacology: There are many cooking recipes, medicines, rituals and orthodox beliefs that we many a time come across which have some or other organic molecules involved in it. One may discover and bring the real chemistry of such molecules in front of the society

- Sonochemistry and Microwave-assisted reaction: A modern-day well established organic laboratory generally has a scientific sonicator and microwave oven at their place. It is a well-known fact now that the ultrasound and microwave assist practically to the organic reactions to a greater extent. Prior search on the sonochemistry as microwave-assisted reaction reported reactions may generate few new ideas and possibilities in this space of organic synthesis.

- Catalysis is a gigantic part of the chemistry faculty where almost all the disciples of chemistry work on, organic synthesis using catalysts is well known, and still lot of challenges yet to answered, one can start with simple possible strategies either using biochemical enzymes or an inorganic or 
organic compound as a potential catalyst. Such research is a little expensive but can yield good experience and publications out of it.

- Photochemistry is another exciting field in organic synthesis, recently reported chiral photosynthesis (Genzink, et. al., 2021) creates an avalanche in this area. The number of things required to do the photochemistry is quite less as compared to the classical total synthesis of organic molecules. Starting from UV lamps to LED varieties of photochemical wells can be easily prepared and used for experimenting with photochemistry. This also creates an unattended opportunity for entrepreneurship in the photochemical instrument and equipment preparation (Buglioni, Raymenants, Slattery, Zondag \& Noel, 2021).

- Mechanochemistry: Can you imagine a mortar and pestle can be an important asset for organic synthesis? Yes, in recent times people are exploring mechanochemistry using ceramic or Zirconium balls as a tool for the synthesis of organic molecules. This area is new and a lot of new happening that things can be done at ease in this emerging field (Virieux, Delogu, Porcheddu, Garca \& Colacino, 2021).

- Green reaction: With the increasing environmental awareness people are in great search of alternatives on the previously reported socially important but hazardous chemical reaction and the methods of preparation of organic molecules. Based on the twelve principles of green chemistry, one can invent a newer possibility in this essential area.

- Interdisciplinary approach: Material Science such as batteries and energy harvesting are the tentacles of advanced organic chemistry, so do not miss these horizons as it has been observed that an interdisciplinary approach is logical and workable.

- Avenues in polymer chemistry: Most organic reactions that land up with polymerization can be viewed as opportunities instead of failure. There are tremendous applications of organic reactions in polymer reactions which avenues to the person. The following lab independent strategies can be also explicitly adopted.

\section{Laboratory Independent Strategies and Tools}

- Review writing: Literature survey plays an important role in one's understanding of organic chemistry in wholesome scenario so that he/she can speak and understand the concept very easily and literature provides very basic information which should not be the candidate should have known from the experience of others. If you want to take an experience of everything it will take a lot of time and will not be practical so literature gives you an insight into what has happened in the past and what can be done in the future. There are the literature managers like endnote and Mendeleev and many more which fetch gives and a tool to gather and the sources in libraries about the topics on which a candidate has a genuine interest. Having pre $\mathrm{PhD}$ publications is always better and may reduce the year in obtaining a $\mathrm{PhD}$. Scientific writing skills are important to communicate and convince the work that you have done (Richardson, Bella, Mougel \& Milic, 2021). It has been observed in general that reviews articles get more citations than articles. Scientific writing is an art and one must master this in order to conquer the higher goals in the science career (Hites, 2021).

- Citation Manager: The newer method of referencing rendering caused by the invention of information technology has given a powerful tool to science workers to work smartly and efficiently. One can certainly invest some amount of time to learn this citation manager software. viz, Endnote, Mendeley, Zotero etc.

- Thought alignment: Interview the experienced faculty or person in the field. Train the brain to think beyond time. Here is one example: An intermediate student may think that he will synthesize Dglucose and when he enters undergraduate, he learns that the $D$-glucose was already synthesized in 1925. An undergraduate student may think that he will synthesize longifolene and when he enters postgraduate studies, he learns that the longifolene was already synthesized by E. J. Corey way back in 1961. A PhD student realized the idea he is thinking of working on has just been published two months ago. A visionary may think of searching for a catalyst that converts vegetable oil to 
acetylene, hydrogen or methane as a green and clean energy solution; there is the need to get the thought beyond the time and try to catch a solution that may be practical in the coming years.

- Gain knowledge regarding research methodology: Enhance the working in organic laboratory skills, attend training programs, conferences, workshops that will strengthen your curriculum vitae.

- If you are interested in medicinal chemistry research, then one should go for studying docking programs like Autodock Vina. This platform is available for molecular docking to the starting beginner level where the concepts of docking can be understood. This software is freely available and has very good library access and optimization. https://www.rcsb.org/ is the protein data bank (PDB) available through the worldwide collaboration of scientists.

- Global programs on lipidomics: There are few programs run all over the world which remained under cover for a long time, lipidomics is one of them. This is the branch of chemistry that deals only with non-polar compounds and its application to medical sciences.

- Chemoinformatics and bioinformatics: If you have inclination towards data science and computer programs then you can try on these fields of chemistry where one can excel through computer programming knowledge

- Induction courses, online webinars, company-sponsored webinars, motivational speeches are some of the online programs which will keep your morale high. Most of such programs you may find free of cost.

- Learn NMR machine operating online, this training is now available nowadays, which will equip you with the often required spectroscopic techniques to organic chemistry.

- Reasonable statistical methods and plotting Tools are very essential in any quantitative research so please fulfil this prerequisite before entering into a $\mathrm{PhD}$ program.

- During the PhD program frequently you will have to prepare PowerPoint and poster presentations, so it will be great self-help to you if you enroll or somehow acquire this knowledge.

- Teaching assistantship: You learn a lot if you teach the same topic to somebody. This leads your understanding to a better level. Before heading to higher education you may supports primary teacher to support and learn from the same activity (Chimonidou, Ludwig \& Marinova, 2021).

- Plagiarism: It is advised to new students to have a piece of knowledge about plagiarism.

- Intellectual property rights and copyright: It will have great assistance to be in a competitive world to protect your intellectual rights. Industrial experience: 1-2 years of industrial experience is always considered when it comes to the selection of the candidate for any program. Here candidates not only get practical knowledge in organic discipline but also learn interpersonal skills.

- Entrepreneurship: if you are a science student with little inclination towards engineering then do not miss the opportunities in instruments, glass blowing and special purpose equipment in organic laboratories. As very few people have such insight in this area. Try for a different startup as well. (Buglioni, Raymenants, Slattery, Zondag \& Noel, 2021).

- Writing a proposal: In research, most of the time candidates have to seek their own, private or sponsor funding in such cases one may have to write a proposal for the same. This may include project writing for the specific purpose or outcome you foresee in your research. There are various funding agencies available for the $\mathrm{PhD}$ students in India (Harikrishna, Jain, Pillai, Dass \& Venugopal, 2020).

- There is a famous wisecrack said, it goes as follows.

First-year Student: My research guide/mentor is great, he is not less than a Nobel laureate.

Second-year Student: I will only publish my articles in a high impact journal.

Third-year Student: Ohh! No! Things don't work as planned.

Fourth-year Guide: We should change the scheme.

Fifth-year Guide: PhD is your problem. I have done mine.

The guide is no longer for students. :)))) 
Have a practical approach to the doctoral program. PhD programs sometimes don't work as we planned, so it is always better to have plan B ready with you at any time. So that you don't cover reliance on the particular thing and this gives you psychological confidence and avoids depression.

\section{CONCLUSION}

In explicit, the article articulates the lab dependent and lab independent strategies and tools that will help organic chemists to visualize newer possibilities in their careers while moving towards their $\mathrm{PhD}$ program.

\section{ACKNOWLEDGEMENT}

My sincere thanks to Deccan Education Society's Fergusson College, Autonomous, Pune for their constant motivation.

\section{REFERENCES}

Armarego, W.F.L., \& Perrin, D.D. (2000). Purification of laboratory chemicals (4th ed.). Oxford, Butterworth Heinmann.

Buglioni, L., Raymenants, F., Slattery, A., Zondag, S.D.A., \& Noel, T. (2021). Technological Innovations in Photochemistry for Organic Synthesis: Flow Chemistry, High-Throughput Experimentation, Scale-up, and Photoelectrochemistry. Chemical Reviews, in press.

Chimonidou, A., Ludwig, R.R., \& Marinova, I. (2021). Supporting Pre-Service Primary School Teacher with Hands-on-Science. Journal of Higher Education Theory and Practice, 21(6), 148-158.

El-Elimat, T., Figueroa, M., Raja, H.A., Graf, T.N., Adcock, A.F., Kroll, D.J., . . Oberlies, N.H. (2013). Benzoquinones and Terphenyl Compounds as Phosphodiesterase-4B Inhibitors from a Fungus of the Order Chaetothyriales (MSX 47445). Journal of Natural Products, 76(3), 382-387.

Firke, N.P., Markandeya, A.G., Deshmukh, R.S.K., \& Pingale, S.S. (2014). Synthesis and Bio-Film Inhibition Activity of Betulinan C and its Analogs. Research Journal of Pharmacy and Technology, 8(1), 54-58.

Firke, N.P., Markandeya, A.G., Deshmukh, R.S.K., \& Pingale, S.S. (2018). Synthesis and Antibacterial Activity of Farinomalein and Its Analogues. Journal of Medicianla and Organic Chemistry Asian Journal of Organic and Medicinal Chemistry, 3(1), 10-13.

Genzink, M.J., Kidd, J.B., Swords, W.B., \& Yoon, T.P. (2021). Chiral Photocatalyst Structures in Asymmetric Photochemical Synthesis. Chemical Reviews, in press.

Harikrishna, M., Jain, S., Pillai, M., Dass, S.H., \& Venugopal N. (2020). Means to a Beginning, Funding opportunities for PhD students and Postdocs in India. Banglore, KA-Indiabioscience.

Hites, R.A. (2021). How to convince an editor to accept your paper quickly. Science of The Total Environment, 798, 149243.

Laursen, S.L., \& Weston, T.J. (2014). Trends in Ph.D. Productivity and Diversity in Top-50 U.S. Chemistry Departments: An Institutional Analysis. Journal of Chemical Education, 91(11), 1762-1776.

Nicolaou, K.C., Sorensen, E.J., \& Winssinger, N. (1998). The Art and Science of Organic and Natural Products Synthesis. Journal of Chemical Education, 75(10), 1225-1258.

Richardson, S.M., Bella, F., Mougel, V., \& Milic, J.V. (2021). Scientific writing and publishing for earlycareer researchers from the perspective of young chemists. Journal of Material Chemistry A, 9(35), 18674-18680.

Tantillo, D.J. (2021). Drawing Polycyclic Molecules. ACS Omega, 6(36), 23008-23014.

Virieux, D., Delogu, F., Porcheddu, A., Garca, F., \& Colacino, E. (2021). Mechanochemical Rearrangements. Journal of Organic Chemistry, 86(20), 13885-13894.

Williams, D.B.G., \& Lawton, M. (2010). Drying of Organic Solvents: Quantitative Evaluation of the Efficiency of Several Desiccants. Journal of Organic Chemistry, 75(24), 8351-8354. 